\title{
Implementing Rainwater Harvesting Methods- A study in Baishnabghata-Patuli, Kolkata, India
}

\author{
Dr. Priyadarshini Sen \\ Lecturer Department of Geography DumDum Motijheel College, Kolkata-700094
}

\begin{abstract}
Rainwater harvesting emerges as the most suitable alternative to combat the water scarcity issues throughout the world, especially for India where adequacy of monsoonal rainfall is perhaps not a major concern but its unthoughtful wastage through overland flow and surface runoff pose a scope for enhanced attention. Harvesting rainwater and making it available in the dry season could have major implications for agriculture and livelihoods in the rural areas and make living easy in urban areas. The city of Kolkata is carrying unbearable load of population where the civic facilities are insufficient, poor and old for the growing population. Thus various efforts are made in order to reduce such problems both at the macro level and micro level. One of such efforts has been the establishment of a new urban area, namely, Baishnabghata-Patuli located in the southeastern fringes of the city proper. The new area has been the brainchild of Kolkata Metropolitan Development Authority, and the project is highly appreciable in the view of sharing excessive population loads on the city of Kolkata providing all kinds of living accommodations. Baishnabghata-Patuli can be termed as a satellite township decorated with all kinds of civic amenities; it has provisions for residential, commercial and institutional plots as per proper town planning norms-maintaining feeder roads at all the possible important junctions to the city proper. The new area provides residences for families of lower, middle and high-income groups with proper sanitation and other civic facilities; even considering the question of environmental problem. Objective of the study here is that how the new planned area copes with the water scarcity issues with the newer methods of Rainwater Harvesting which can be treated as a indicative pathway for the rest.
\end{abstract}

Keywords: Baishnabghata-Patuli, Groundwater Recharge, Megacity, Rainwater Harvesting, Recharge wells

\section{Introduction}

The basic necessity to study an urban area like Baishnabghata-Patuli at the micro level accounts for the development and achievements of any kind of Planning Authority in making an urban zone that will be selfcontained to release the pressure of excessive population in the metropolitan city. The need for providing spatial assistance to the people of Kolkata Metropolitan Area by the Government of India and Planning Commission as well has been felt in late. In response to this, Kolkata Metropolitan Development Authority, prepared a Report in August 1990, named 'Plan for Metropolitan Development-1995-2015'. In that Report the portrait of future metropolis, its future economy, spatial structure, future settlement areas and land use patterns were presented. Later the matter was discussed between the Government of India and West Bengal and a document entitled 'Calcutta Mega city Programme-Project proposal' prepared in April 1993, was forwarded to the Planning Commission by the State of West Bengal. In the procedure, an investment outline of INR 1600 crores was also given. Therefore the city of Kolkata now looks forward to a dynamic and revitalized bright future; but this definitely demands sustained efforts of planning and implementation of strategies in the right directions over the future years. There is still a huge backlog of accumulated deficits in the infrastructural facilities and services that have to be wiped out. Besides, millions of people would have to be provided with shelter, civic services, health and education facilities and thousands of jobs would have to be generated to stabilize and expand the employment structure.

II. Area Of Study

Baishnabghata-Patuli is the new area that has been situated in the south-eastern fringes of Kolkata, designed to accommodate housing facilities to the growing population.The Planning Authority, KMDA, mentioned that the nature of this new area development should be such that it would make the optimum use of land resources safeguarding the aims of sustainable urban land use in this particular area. The area is to provide necessary infrastructural facilities, open spaces, community facilities and greeneries. It would be surprising to note that the eastern part of the city of Kolkata registered a growth rate of 151 percent and above, compared to the growth rate of 7.2 percent in the proper Kolkata corporation area during the period of 1961-1971. Though the population growth in the city fringes has been alarmingly high but remained very unevenly, definitely haphazardly distributed in these areas. 


\section{Why Rainwater Harvesting In Study Area?}

The question may arise why Rainwater Harvesting is being implemented in a new area like Baishnabghata-Patuli where basic amenities like water supply have been assured. But the household survey conducted by the author revealed that $40 \%$ of the surveyed families mentioned that scarcity of water for domestic purpose is prevalent in the area and reaches maximum in the summer months (Fig.1). Compared to other problems like dust and noise pollution, water scarcity perhaps poses the biggest challenge in this new residential area.

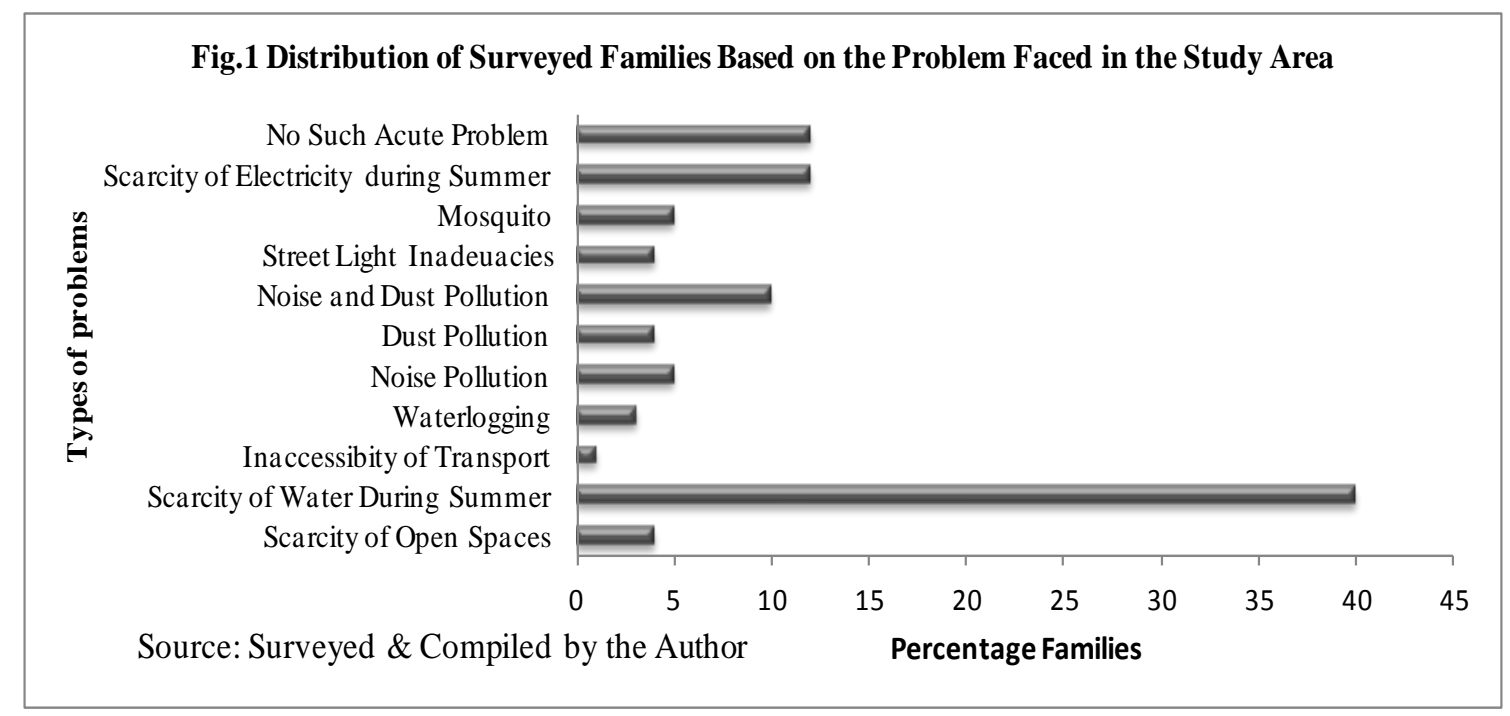

Therefore the development perspective of this area should make provisions for sustainable urban land use in order to promote better livability in the new area. One such methodology to maintain such sustainable ideology is rainwater harvesting practiced in the study area first of its kind in Kolkata .Rainwater harvesting in urban areas is designated to collect rainwater falling on the roof top or paved areas so as to conserve noncommitted surplus monsoon runoff as much as possible, either at the surface or in sub-surface reservoir (aquifer).Ever increasing demand for fresh water by burgeoning population needed accelerated development of ground water as surface water supply is mostly inadequate. So the ground water supply in the city is facing a scarcity and it is a matter of fact that the ground water level in the deeper confined productive aquifer of the city has already declined to around 3 to5 meters within a span of over a decade (Fig.2). The trend of groundwater fluctuations are such that round the year, the water level below the ground falls well below the mean level during October and gains somewhat during the November and December .Such seasonal fluctuations are commonly occurring in this area that has been proposed to tackle through Artificial Recharge of ground water through the conservation of rainwater.

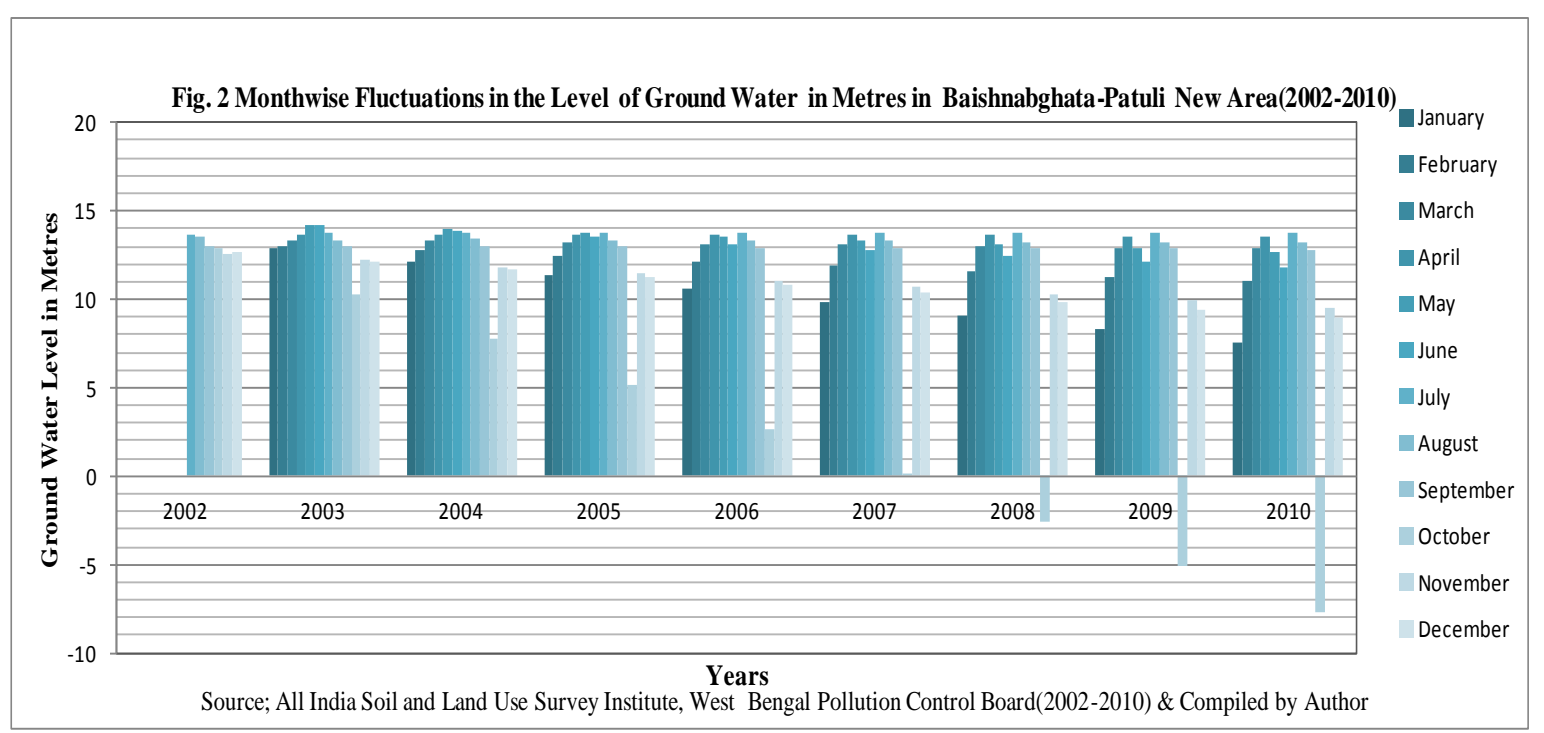


In order to cope with such critical situation, there has been a cost effective option to artificially recharge ground water. For Kolkata, the aim was to develop appropriate technology for recharging deeper confined areas and that was first introduced in the city at Baishnabghata-Patuli in the year 2002 by Arden Centre, Kolkata with funding from Central Ground Water Board. Here harvesting and recharging structures included water conveyance system, control units, collecting chambers with filter beds and recharge well. Recharging ground water aquifers depends on the geological setting of the area whether aquifer is confined or unconfined and in recharge zone. However in urban areas like this it can be done by either Rooftop rainwater harvesting through recharge pit or Rooftop rainwater harvesting through recharge trench or harvesting through existing tube wells or trench (linked to recharge wells)with associated filtration mechanisms.

\section{Hydrogeological Setup Of Study Area}

The Project area is underlain by a thick layer of impervious clay up to 27 metres below ground level from the surface and it is underlain by thin layer of sand of $3 \mathrm{~m}$ thickness. This sand layer is followed by thick layer of clay down to a depth of 49 metres below ground level. The productive aquifer consisting of fine to medium grained sand occurs below this clay layer down to the explored depth of 152.45 metres below ground level. However, depth of water level varies from 14.68metres below ground level to 16.32 metres below ground level in pre monsoon period and from 13.41 metres below ground level to 15.71 metres below ground level in post monsoon period. The study reveals that the presence of thick clay layer near the surface in Kolkata city area act as a barrier to the natural ground water recharge to the underlying aquifers which should be treated with modern methods of modifying the passages of conserved water in to the ground water. The rain water harvesting project has been carried out here on the roof of Office Complex of All India Soil and Land Use Survey, government of India. Hydrogeology of the project area is to be understood in the background of the hydrogeology of Kolkata and its associated areas of North and South 24 Parganas.The area is underlain by quarternary sediments. Alternative sequence of clay, silty clay, sand and sandy clay constitute the geology of this terrain. At the top of these layers lies the clay horizon ranging in thickness from 30-50 metres. Below it there is the granular zone (fine to medium grain sand, with occasional gravels) which forms the confined aquifer. This is the productive aquifer of the city, and the depth of it ranges between 40 to 100 metres in the northern part, 50-160 metres in the central and southern part and 180-300 metres in the south-western part. Comparatively shallower unconfined aquifer with limited potential occur in linear patches in some parts in some parts of south Kolkata and further south within the depth range of 20-40 metres.

Table (1) Approximate Cost of Recharge Structure in Mrittika Bhavan, Baishnabghata-Patuli.Kolkata

\begin{tabular}{|c|c|c|}
\hline \multicolumn{2}{|c|}{ Recharge structure } & Approximate cost(INR) \\
\hline \multicolumn{2}{|c|}{ Recharge pit } & $2500-5000$ \\
\hline \multicolumn{2}{|c|}{ Recharge Trench } & $5000-10,000$ \\
\hline \multicolumn{2}{|c|}{ Recharge through Hand pump } & $1500-2500$ \\
\hline \multicolumn{2}{|c|}{ Recharge through Dug well } & $5000-8000$ \\
\hline \multicolumn{2}{|c|}{ Recharge Well } & $50,000-80,000$ \\
\hline \multicolumn{2}{|c|}{ Recharge Shaft } & $60,000-85,000$ \\
\hline \multirow{2}{*}{$\begin{array}{c}\text { Lateral Shaft with } \\
\text { boreholes; }\end{array}$} & a)shaft per metres & $2000-3000$ \\
\hline & b) bore well & $25,000-35,000$ \\
\hline
\end{tabular}

Source; All India Soil and Land Use Survey Institute, West Bengal Pollution Control Board(2006)

In the above Table (1) the cost estimates of recharge systems in the study area are outlined. The basic purpose of rainwater harvesting in urban areas is to collect and conserve non-committed surplus monsoon runoff, either at surface or in sub-surface aquifer, before it is lost to sewer or storm -water drains. Rain water, the primary form of fresh water, has always been harvested since generations, using indigenous techniques, suitable for a particular area. But harvesting of water falling on rooftops and paved areas, to artificially recharge ground water is a relatively new technique with great potential. Natural recharge to ground water is a pretty slow process, particularly in concretized urban areas and this fails to cope with the rapid demand of ground water. Harvesting for the purpose of artificial recharge to ground water is the most appropriate and economically viable proposition for urban area and the advantages of over surface storage as outlined by the Central Ground Water Board are; 
- Little space is required for recharge structure.

- Cost of recharging is quite lower than the storage and proper maintenance cost at the surface.

- Sub-surface reservoir that is the aquifers can serve the 'warehouse' for storing substantial quantity of water and the aquifer serves as a distribution system also.

- Recharge allows eco-friendly storage not directly exposed to pollution or evaporation.

- Replenishment of ground water resource enhances sustainable yield from aquifer.

- Quality of water improves through dilution by rainwater.

However, surface storage serves limited but very useful purpose in areas of water scarcity, if practiced for individual households or small size residential complexes, provided proper care is taken for filtration and contamination -free maintenance .It may also supplement the need for water other than drinking and cooking. A summarized account of rooftop water harvesting project in the study area may be grouped as a study to harvest rooftop rainwater and recharge productive aquifer (deeper confined aquifers) and its impact of recharging on existing ground water quality and peizometric head of deeper aquifers. This process is indeed important to assess the rate of recharge and storage potential (Table 2).

Table (2) Rainwater Harvesting Potentials in the Study Area

\begin{tabular}{|c|c|}
\hline Harvesting Potentials & Units \\
\hline Normal Average Annual Rainfall & 1500 Millimetres \\
\hline Monsoonal Rainfall & 1050 MIllimetres \\
\hline Catchment Area or Rooftop Area in Mrittika Bhavan & 676 Square Metres \\
\hline Ruantity of Annual Rainwater Available for Recharge & 811.20 Cubic Metres \\
\hline Recharge during Monsoon & 567.84 Cubic Metres \\
\hline
\end{tabular}

Source; All India Soil and Land Use Survey Institute, West Bengal Pollution Control Board (2006)

The rooftop of the Building of All India Soil and Land Use Survey has served as catchment, and the water conveyance pipe line is connected to roof drain. Besides control units or chlorinated chambers are connected to the roof drain. Besides the recharge pit acting as collecting and filtering chamber connected through the pipe to the chlorinated chamber and the recharge pit is again backfilled with boulder, gravels and coarser sand. Besides, two gravity -head recharge wells within the pit are fitted well so that the filtered water sits into these wells in its journey to the aquifer. The harvested water has agreeable taste and odour and $\mathrm{pH}$ levels which is satisfactory to be utilized for domestic purposes(Table 3).

Table (3) Various Aspects of the Harvested Rainwater in Baishnabghata-Patuli New Area

\begin{tabular}{|c|c|}
\hline Aspects & Types or Units \\
\hline Aquifer materials & Fine to Medium Sand \\
\hline Number of recharge well & 2 \\
\hline Stamet o recharge wells & 150 Milimetres \\
\hline Th of the Harvested Water & 13.00 Metres below Ground level \\
\hline Taste of the Harvested Water & Agreeable \\
\hline Odour of the Harvested Water & Unobjectionable \\
\hline
\end{tabular}

Source; All India Soil and Land Use Survey Institute, West Bengal Pollution Control Board (2006)

\section{Conclusion}

Broadly speaking the objectives of this project in the study area has been achieved .Leaving aside the fact of huge amount of fresh water being recharged throughout the year and the consequent localized rise in peizometric head the most important outcome is the satisfactory rates of recharge and recharge potentials of the deeper confined aquifer on the solid base. It is well established that the aquifer has the capacity to absorb large quantity of rain water keeping pace with the sudden outbreak of rain. Thus it is seen that in the study area of Baishnabghata-Patuli, there has been application of latest technology of rainwater harvesting which is expected to reduce the scarcity of potable water in the area in concern. There has been successful application of ground water recharging activities in the area that has been citing great examples to the other new urban areas or townships yet to be developed in other parts of the country. 


\section{Reference}

[1] A report on Baishnabghata-Patuli Area Development Plan(No. 19), (19th January 1976)published by KMDA, Urban development Circle ,Directorate of Planning,

[2] A report on Baishnabghata-Patuli Area Development Plan, revised (No. 58), (April 1978)published by KMDA, Urban development Circle ,Directorate of Planning

[3] A report on Physical Survey of Baishnabghata-Patuli project Area-Part A, Eastern Part of Eastern Metropolitan By-Pass, including Eastern Metropolitan by- Pass(1992-1993) published by Kolkata metropolitan Development Authority.

[4] A report on Physical Survey of Baishnabghata-Patuli project Area-Part B, Western Part of Eastern Metropolitan by- Pass, including Eastern Metropolitan by- Pass.(1992-1993),published by Kolkata metropolitan Development Authority.

[5] A report on KMDA profile-'Tackling the various challenges in urban development', published by KMDA, Planning Circle.

[6] Taron P.B., Bannerjee Indranil, Lahiri S.N,' A Report on rainwater harvesting in urban areas; guidelines and techniques for Kolkata', All India Seminar on global Trends in Building service engineering.

[7] A report on 'Rainwater harvesting in Baishnabghata-Patuli, Kolkata', published by West Bengal Pollution control Board, Paribesh Bhavan, Kolkata. 